\title{
Extraction and Purification of a Lectin from Red Kidney Bean and Preliminary Immune Function Studies of the Lectin and Four Chinese Herbal Polysaccharides
}

\author{
Yufang Hou, ${ }^{1}$ Yubao Hou, ${ }^{2}$ Liu Yanyan,, ${ }^{1}$ Guang Qin, ${ }^{1}$ and Jichang Li $^{1}$ \\ ${ }^{1}$ College of Veterinary Medicine, Northeast Agricultural University, 59 Mucai Street, Xiangfang District, Harbin 150030, China \\ ${ }^{2}$ Traditional Chinese Medical Hospital of Huaiyuan County, Bengbu 233400, China \\ Correspondence should be addressed to Jichang Li, lijichang828@sina.com
}

Received 2 February 2010; Revised 9 May 2010; Accepted 20 July 2010

Academic Editor: Elvira Gonzalez De Mejia

Copyright () 2010 Yufang Hou et al. This is an open access article distributed under the Creative Commons Attribution License, which permits unrestricted use, distribution, and reproduction in any medium, provided the original work is properly cited.

\begin{abstract}
Reversed micelles were used to extract lectin from red kidney beans and factors affecting reverse micellar systems ( $\mathrm{pH}$ value, ionic strength and extraction time) were studied. The optimal conditions were extraction at $\mathrm{pH} 4-6$, back extraction at $\mathrm{pH} 9-11$, ion strength at $0.15 \mathrm{M} \mathrm{NaCl}$, extraction for 4-6 minutes and back extraction for 8 minutes. The reverse micellar system was compared with traditional extraction methods and demonstrated to be a time-saving method for the extraction of red kidney bean lectin. Mitogenic activity of the lectin was reasonably good compared with commercial phytohemagglutinin (extracted from Phaseolus vulgaris) Mitogenic properties of the lectin were enhanced when four Chinese herbal polysaccharides were applied concurrently, among which $50 \mu \mathrm{g} / \mathrm{mL}$ Astragalus mongholicus polysaccharides (APS) with $12.5 \mu \mathrm{g} / \mathrm{mL}$ red kidney bean lectin yielded the highest mitogenic activity and $100 \mathrm{mg} / \mathrm{kg} / \mathrm{bw}$ APS with $12.5 \mathrm{mg} / \mathrm{kg} / \mathrm{bw}$ red kidney bean lectin elevated mouse nonspecific immunity.
\end{abstract}

\section{Introduction}

Lectins are carbohydrate-binding proteins, which are highly variable in their amino acid sequences, widely distributed in microorganisms, viruses, animals and higher plants [1], and with different functions, structures, tissue localizations and carbohydrate-binding specificities. Plant lectins were classified into seven families according to their evolutionary and structural characteristics by Van Damme et al. [2], one of which is the legume lectin family. Among the numerous lectins studied, those of the legumes occupy a special position, since they represent the largest and most thoroughly studied family of these proteins [3]. The leguminous seed lectins show a remarkable conservation in primary, secondary, and tertiary structures. Because of the very similar tertiary structures and varied quaternary structures [4], legume lectins have become an excellent model to analyze the role of primary structure in determining the modes of quaternary association. A number of diverse physiological roles have been proposed for these proteins, including mitogenic $[5,6]$, antifungal $[7]$, antiviral $[8,9]$, anti-insect
$[10,11]$, and antitumor $[6,12-15]$ activities. Their sugarbinding properties are also used as molecular tools to study glycoconjugates or for drug delivery and targeting $[16,17]$.

There are many problems to overcome during preparation of lectins, such as a low extraction rate, purification difficulties, and high extraction cost, which restricts the application of lectins.

Lectin extraction is usually achieved using different methods of diffusion in aqueous solution and ammonium sulfate precipitation. Problems with these methods include cumbersome operations, a low extraction rate, hard to extract hand-running and amplify, which universally exist in the separation and purification of biomolecules. To solve these problems, alternative techniques have received particular attention, such as liquid-liquid extraction with reversed micelles. In this paper, reversed micelles were used and compared with traditional methods for the extraction of red kidney bean lectin.

Polysaccharides isolated from a variety of traditional medicinal plants can greatly stimulate immune system in vivo and in vitro, therefore, they have the potential 
to be immunomodulators with wide applications [18-20]. Most polysaccharides derived from traditional medicinal plants are relatively nontoxic and do not cause significant side effects, which are major problems associated with immunomodulatory bacterial polysaccharides and synthetic compounds. Thus, plant polysaccharides are ideal candidates for therapeutics [18] and three polysaccharides (lentinan, schizophyllan and krestin) were accepted as immunoceuticals in several Oriental countries in 2002 [19]. In this work, mitogenic activity of red kidney bean lectin and four Chinese herbal polysaccharides (CHPs) were applied together to detect if the immunomodulatory activities were enhanced.

\section{Materials and Methods}

2.1. Materials. Red kidney beans were purchased from a local supermarket in Heilongjiang Province, China. Chinese herbal medicines were obtained from Siyitang Company (Harbin, China). 3-(4,5-Dimethylthiazol-2-yl)-2,5diphenyltetrazolium bromide (MTT) and electrophoretic reagents were purchased from Sigma (Sigma Aldrich China). DEAE Sephadex A-50 and Sephadex G-150 were obtained from GE Healthcare (USA). Other reagents of the highest purity available were obtained from local suppliers. Sixto eight-week-old female Kunming mice, each weighing approximately $20 \mathrm{~g}$, were obtained from the laboratory animal center in the 2nd affiliated hospital of Harbin Medicine University. Standard mouse chow and drinking water solutions were fed ad libitum.

\subsection{Isolation of Red Kidney Bean Lectin}

\subsubsection{Traditional Methods}

(1) Soaking Method. Red kidney beans were ground to a powder in an electric mill and filtered through 80 mesh grit. The powder $(5 \mathrm{~g})$ was mixed with $0.15 \mathrm{M} \mathrm{NaCl}(1: 8, \mathrm{w} / \mathrm{v})$ for $48 \mathrm{~h}$ at $4^{\circ} \mathrm{C}$, and filtered through 80 mesh grid. Subsequently, the filtrate was centrifuged at $9168 \times \mathrm{g}$ for 30 minutes, and the supernatant was fractionally precipitated with ammonium sulfate at $40 \%, 50 \%, 60 \%$, and $70 \%$ saturation, respectively. The four pellets were combined, dissolved in a minimal volume of water, and dialyzed against distilled water at $4^{\circ} \mathrm{C}$.

(2) Degreasing Method. The powder was defatted twice with Sherwood oil $(1: 8, \mathrm{w} / \mathrm{v})$ for $4 \mathrm{~h}$ at $4^{\circ} \mathrm{C}$, which was removed by volatilization at room temperature, to obtain degreased bean powder. The degreased bean powder was mixed with $0.15 \mathrm{M}$ $\mathrm{NaCl}(1: 8, \mathrm{w} / \mathrm{v})$ for $48 \mathrm{~h}$ at $4^{\circ} \mathrm{C}$, and subsequent procedures were identical to those described in Section 2.2.1.(1).

(3) Homogenate Method. Red kidney beans (5 g) were softened in $400 \mathrm{~mL} \mathrm{NaCl}(1: 8, \mathrm{w} / \mathrm{v})$ for 24 hours at $4^{\circ} \mathrm{C}$, then homogenized in a blender. The homogenate was diffused for a further 24 hours at $4^{\circ} \mathrm{C}$, then filtered through an 80 mesh grid. The filtrate was centrifuged at $9168 \times g$ for 30 minutes, and the supernatant was precipitated hierarchically by ammonium sulfate.
To evaluate the protein concentration and hemagglutinating activity of each extract, all extracts were adjusted to the same volume using polyethylene glycol 20000 when necessary.

2.2.2. Reversed Micelle Extraction. The reverse micellar system comprised sodium di-(2-ethylhexyl) sulfosuccinate $(\mathrm{AOT})$ in isooctane. Extraction and back extraction assays were performed by phase contact 1:1 (v/v), stirred for 5 minutes and separated by centrifugation at $2292 \times g$ for 5 minutes following the method of Nascimento et al. [20].

Single factor analysis was used to assess the effects of aqueous phase $\mathrm{pH}$, extraction time and aqueous phase ion strength on reversed micelle extraction.

2.3. Determination of Protein Concentration. Bradford's method [21] was used for protein quantification, using bovine serum albumin (BSA) as the standard. The relative protein concentration of the eluted fractions was determined by measuring the absorbance at $280 \mathrm{~nm}$.

2.4. Hemagglutinating Activity Assay. Serial two-fold dilutions of the lectin solution in microtiter v-plates $(25 \mu \mathrm{L})$ was mixed with $25 \mu \mathrm{L} 2 \%$ chicken red blood cell suspension in saline ( $\mathrm{pH}$ 7.2). Readings were recorded after about 30 minutes at room temperature, when the blank had fully sedimented. The hemagglutination titer, defined as the reciprocal of the highest dilution exhibiting hemagglutination, was treated as one hemagglutination unit. Specific activity was expressed as the number of hemagglutination units per mg protein.

2.5. Purification of Red Kidney Bean Lectin. Crude extract from reversed micelles was dialyzed against $0.1 \mathrm{M} \mathrm{NaCl}$ in $0.02 \mathrm{M}$ Tris- $\mathrm{HCl}$ ( $\mathrm{pH} 8.0$ ), loaded on a DEAE Sephadex A-50 column $(2.6 \mathrm{~cm} \times 60 \mathrm{~cm})$ that had been equilibrated with the same buffer, and subjected to ion exchange chromatography. The column was washed initially with $0.1 \mathrm{M} \mathrm{NaCl}$ in $0.02 \mathrm{M}$ Tris- $\mathrm{HCl}(\mathrm{pH}$ 8.0) to remove proteins that had not specifically absorbed to the column, then washed with linear salt gradient elution. Fractions showing hemagglutinating activity were further purified by sieve chromatography on a Sephadex G150 column in $0.15 \mathrm{M} \mathrm{NaCl}$ in $0.02 \mathrm{M}$ Tris- $\mathrm{HCl}$ ( $\mathrm{pH} 8.0$ ).

2.6. SDS-PAGE. Sodium dodecyl sulfate polyacrylamide gel electrophoresis (SDS-PAGE) was performed in accordance with the method of Laemmli et al. [22], using a $15 \%$ separating and a $5 \%$ stacking gel.

2.7. Extraction and Purification of Chinese Herbal Polysaccharides (CHPs). Powders ground from four Chinese medicinal materials (Astragalus mongholicus, Poria cocos, indigowood root (Isatis indigotica), and Angelica sinensis) were boiled in distilled water for 4 hours at $100^{\circ} \mathrm{C}$. After filtration to remove debris, the filtrates were concentrated in a rotary evaporator. Proteins were removed using the Sevag method [23]. Crude polysaccharide fractions were obtained by 
precipitation with three volumes of ethanol and desiccation in vacuo. The precipitates were redissolved in distilled water and loaded on a D101 macroporous resin column $(2.6 \mathrm{~cm} \times$ $60 \mathrm{~cm})$ to remove pigments. The effluents were collected and polysaccharide fractions were quantitatively determined using a phenol-sulfuric acid assay [24] with glucose as the reference standard.

2.8. Assay of Mitogenic Activity of the Lectin and Four CHPs. Three Kunming mice (20-25 g) were killed by cervical dislocation. The spleens were aseptically removed and pressed through a sterilized 100-mesh stainless steel sieve. Splenic lymphocytes were separated with lymphocyte separation medium and resuspended to a concentration of $2 \times 10^{6}$ cells $/ \mathrm{mL}$ in RPMI 1640 culture medium supplemented with $10 \%$ fetal bovine serum, 100 units $/ \mathrm{mL}$ penicillin and $100 \mu \mathrm{g} / \mathrm{mL}$ streptomycin. The suspensions $(2 \times$ $10^{6}$ cells $/ 90 \mu \mathrm{L} /$ well) were seeded to a 96 -well culture plate, and serial two-fold dilutions of red kidney bean lectin solution $(0.78-200 \mu \mathrm{g} / \mathrm{mL})$ or CHPs solution $(25-400 \mu \mathrm{g} / \mathrm{mL})$ in $10 \mu \mathrm{L}$ medium were added. After incubation for 48 hours at $37^{\circ} \mathrm{C}$ in humidified atmosphere containing $5 \% \mathrm{CO}_{2}, 10 \mu \mathrm{L}$ $0.5 \mathrm{mg} / \mathrm{mL}$ MTT was added, and the cells were incubated for another 4 hours under the same conditions. Finally, $100 \mu \mathrm{L}$ dimethyl sulfoxide (DMSO) was added to each well, oscillated for 1 minute, and the absorbance was measured at $570 \mathrm{~nm}$. The results were expressed as OD values.

According to the mitogenic activity of red kidney bean lectin, an optimal lectin concentration $(12.5 \mu \mathrm{g} / \mathrm{mL})$ was chosen to be applied concurrently with the four CHPs at different concentrations $(0-400 \mu \mathrm{g} / \mathrm{mL})$ to detect whether mitogenic activity was enhanced.

2.9. Effect of Red Kidney Bean Lectin and Astragalus mongholicus Polysaccharide on Mouse Immune Functions. Sixty Kunming mice (20-25g) were randomly divided into six groups, consisting of a saline control group, APS (Astragalus mongholicus polysaccharide) group, lectin group, and lectin together with high, moderate, or low APS dosage group. The mice were maintained in an air-conditioned animal room with an ambient temperature of $21^{\circ} \mathrm{C}, 55 \%$ relative humidity, and $12 \mathrm{~h} / 121$, h light/dark cycle. The animals were provided ad libitum with a basal diet (Institute of Laboratory Animal Science, ingredients: protein $\geq 18 \%$, fat $\geq 4 \%$, fiber $\leq 5 \%$, lysine $\geq 0.82 \%$, calcium $1.0-1.8 \%$, phosphorus $0.6-1.2 \%$, and salt $0.3-0.8 \%$ ) and regularly refreshed tap water. The mice were injected intraperitoneally with $0.5 \mathrm{~mL}$ polysaccharide solution once per day for 5 days. The lectin and high, moderate, or low APS dosage group received $12.5 \mathrm{mg} / \mathrm{kg} / \mathrm{bw}$ lectin and either 100, 50, or $25 \mathrm{mg} / \mathrm{kg} / \mathrm{bw}$ APS, respectively; the APS group was given $100 \mathrm{mg} / \mathrm{kg} / \mathrm{bw}$ APS; the lectin group received $12.5 \mathrm{mg} / \mathrm{kg} / \mathrm{bw}$ red kidney bean lectin; and $0.5 \mathrm{~mL}$ saline was injected in the control group. On the seventh day a carbon particle clearance experiment was carried out, according to Zhang [25], and the spleen index and thymus index were measured. Briefly, $0.05 \mathrm{~mL} / 10 \mathrm{~g} / \mathrm{bw}$ India ink was injected into each mouse through the vena caudalis, then $20 \mu \mathrm{L}$ blood was obtained from the vena orbitalis posterior
3 and 7 minutes after the injection. The blood samples were placed in tubes with $2 \mathrm{~mL} 0.1 \% \mathrm{Na}_{2} \mathrm{CO}_{3}$, and OD values were measured at $600 \mathrm{~nm}$.

The clearance index $(K)$, phagocytic index $(\alpha)$ and immune organ index were calculated as follows, $t_{2}$ and $t_{1}$ means 7 minutes and 3 minutes respectively.

$$
\begin{aligned}
& K=\frac{\left(\log \mathrm{OD}_{3}-\log \mathrm{OD}_{7}\right)}{t_{2}-t_{1}}, \\
& \alpha=\frac{\text { body weight }}{(\text { spleen weight }+ \text { liver weight })^{*} \sqrt[3]{K}}, \\
& \text { Immune organ index }=\frac{\text { immune organ weight }(\mathrm{mg})}{\text { body weight }(\mathrm{g})} \text {. }
\end{aligned}
$$

\section{Results}

3.1. Effects of $p H$, Extraction Time, and Ion Strength on Reversed Micelle Extraction. The $\mathrm{pH}$ value of the aqueous phase affected both extraction and back extraction greatly. The extraction was optimal when the aqueous phase $\mathrm{pH}$ was $4-6$, and for back extraction, the optimal $\mathrm{pH}$ was 9 to 11 (Figure 1(a)). Extraction time also affected reversed micelle extraction. The highest lectin concentration was obtained with an extraction time of 4-6 minutes, beyond which the extraction rate decreased greatly, while the back extraction rate increased as the extraction time increased, but did not increase any further after 8 minutes extraction (Figure 1(b)). The ion strength of the aqueous phase had a major influence on reversed micelle extraction. At $0.05 \mathrm{M}$ $\mathrm{NaCl}$ the aqueous and organic phases could not be detached, at $0.10 \mathrm{M} \mathrm{NaCl}$ detachment was incomplete, at $0.15 \mathrm{M} \mathrm{NaCl}$ complete detachment occurred and according to the curve the extraction effect was the best.

3.2. Extraction Effect. The regression equation of the BSA standard curve was $y=0.6476 x-0.0023\left(R^{2}=0.9992\right)$ and the linear range was $0.2-1.0 \mathrm{mg} / \mathrm{mL}$. The protein concentration of each extract was calculated based on the regression equation, and results showed that the reversed micelle extraction rate of degreased or undegreased ground bean was $7.23 \%$ and $6.25 \%$, while those of traditional extraction methods were $4.27 \%, 5.49 \%$, and $3.04 \%$, respectively (Table 1 ). Mean specific hemagglutinating activity of extracts obtained with the soak, degreasing, and homogenizing methods was 60,187 , and 84 titer/mg, respectively, whereas that of extracts obtained from degreased and undegreased red kidney bean powder with reversed micelles was 283 and 164 titer/mg, respectively (Table 1).

3.3. Purification of Red Kidney Bean Lectin. Three fractions were obtained from ion exchange chromatography (Figure 2 (a)), among which fraction I did not show hemagglutinating activity, and the volume obtained from fraction III was too small, so only fraction II was collected, concentrated and loaded on a Sephadex G-150 column for gel filtration. Fraction II was resolved into a large fraction (fraction IV) 


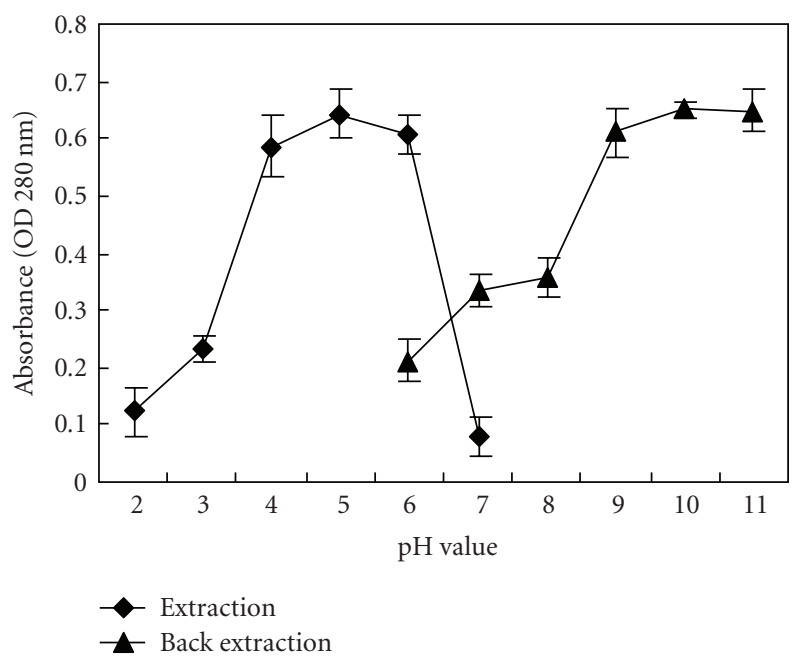

(a)

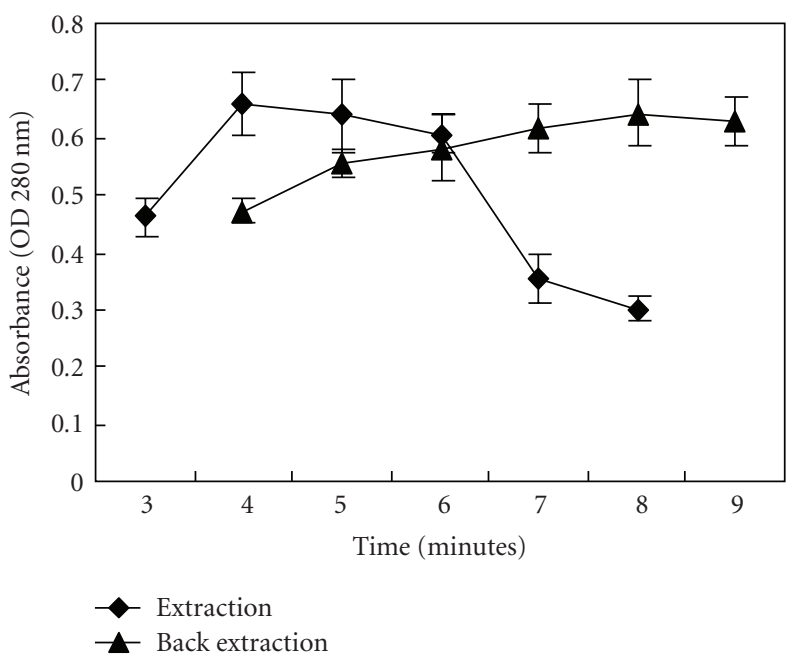

(b)

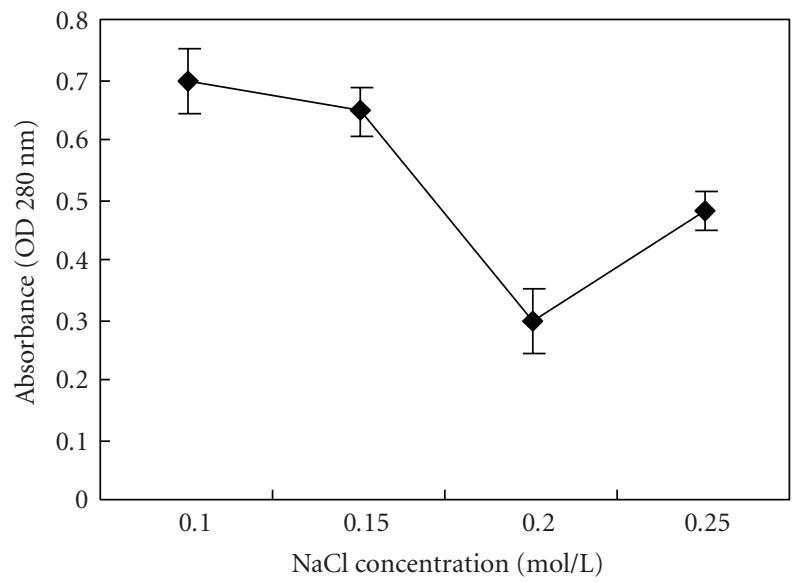

(c)

FigURE 1: Effect of $\mathrm{pH}(\mathrm{a})$, extraction time (b), and ion strength (c) on reversed micelle extraction of red kidney bean lectin. Data represent means $\pm \operatorname{SD}(n=6)$.

TAвLE 1: Protein concentration and hemagglutinating activity of each extract. Data represent means $\pm \operatorname{SD}(n=4)$.

\begin{tabular}{lccccc}
\hline \multicolumn{1}{c}{ Parameter } & \multicolumn{2}{c}{ Traditional method } & \multicolumn{2}{c}{ Reversed micelle extraction } \\
\hline Total protein $(\mathrm{mg})$ & Soak & Degreasing & Homogenizing & Degreased & Undegreased \\
Extraction rate $(\%)$ & $213.39 \pm 21.34$ & $274.51 \pm 15.23$ & $152.22 \pm 13.03$ & $361.52 \pm 19.89$ & $312.54 \pm 17.84$ \\
Specific activity $($ titer $/ \mathrm{mg})$ & $4.27 \%$ & $5.49 \%$ & $3.04 \%$ & $84.23 \%$ & $6.25 \%$ \\
Total activity $\left(\right.$ titer $\left.\times 10^{4}\right)$ & 60 & 187 & 1.28 & 283 & 164 \\
\hline
\end{tabular}

and a very small fraction (fraction V) (Figure 2 (b)). Both fractions showed hemagglutinating activity, but only fraction IV was collected and dialyzed, then stored at $-20^{\circ} \mathrm{C}$. The purified lectin (fraction IV in Figure 2 (b)) formed a single band with a molecular mass of about $30 \mathrm{kDa}$ in SDS-PAGE electrophoresis (Figure 3), which confirmed the effectiveness of the purification method used.

3.4. Extraction of Chinese Herbal Polysaccharides. The regression equation of the glucose standard curve was $y=$ $0.0509 x-0.0149\left(R^{2}=0.9915\right)$ and the linear range was $2-10 \mu \mathrm{g} / \mathrm{mL}$. Based on the standard curve, $3.65 \mathrm{~g}$ APS, $1.22 \mathrm{~g}$ PWP (Poria cocos polysaccharide), $3.214 \mathrm{~g}$ IRP (indigowood root polysaccharide), and $3.55 \mathrm{~g}$ ASP (Angelica sinensis polysaccharide) were extracted from $300 \mathrm{~g}$ Astragalus mongholicus, $200 \mathrm{~g}$ Poria cocos, $300 \mathrm{~g}$ indigowood root, and $300 \mathrm{~g}$ Angelica sinensis, respectively, and the carbohydrate concentration of each was $86 \%, 79 \%, 72 \%$, and $83 \%$, respectively, (Table 2 ).

3.5. Mitogenic Activity. Red kidney bean lectin significantly promoted proliferation of murine splenic lymphocytes at a 


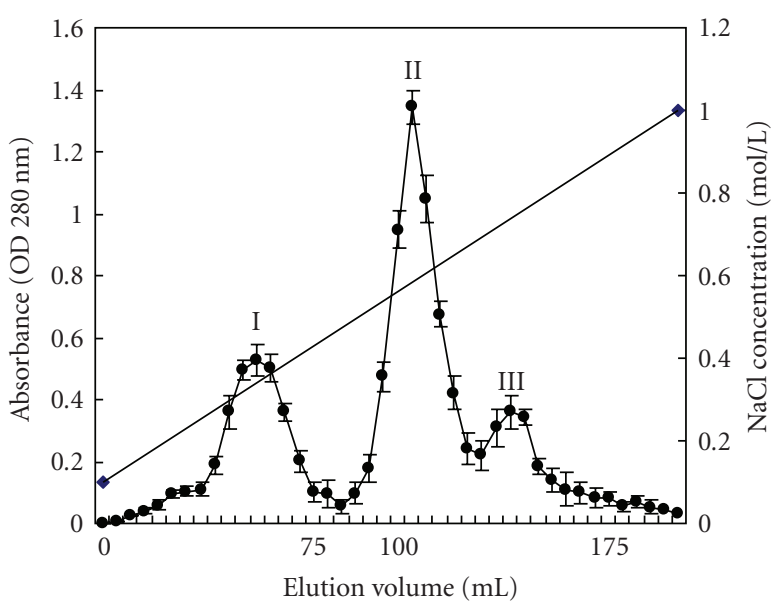

(a)

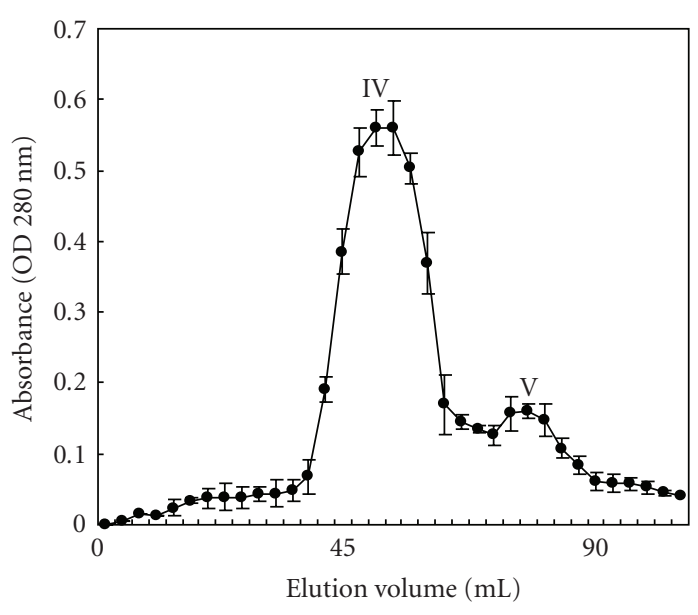

(b)

FIgURE 2: (a) Fractionation of the crude extract of red kidney bean lectin by DEAE Sephadex A-50 ion-exchange chromatography equilibrated with $0.1 \mathrm{M} \mathrm{NaCl}$ in $0.02 \mathrm{M}$ Tris- $\mathrm{HCl}(\mathrm{pH}$ 8.0). The column was washed initially with the same buffer to remove proteins that were not specifically absorbed to the column (data not shown on the figure) then washed with buffer in which the $\mathrm{NaCl}$ concentration increased linearly from $0.1 \mathrm{M}$ to $1.0 \mathrm{M}$. Three peaks were obtained, among which peaks II and III exhibited hemagglutinating activity. Column: $2.6 \mathrm{~cm} \times 60 \mathrm{~cm}$; flow rate: $0.5 \mathrm{~mL} / \mathrm{min}$. (b) Fractionation of peak II on a Sephadex G-150 column with $0.15 \mathrm{M} \mathrm{NaCl}$ in $0.02 \mathrm{M}$ Tris- $\mathrm{HCl}(\mathrm{pH} 8.0)$. Column: $2.6 \mathrm{~cm} \times 60 \mathrm{~cm}$; flow rate: $1 \mathrm{~mL} / \mathrm{min}$. Only the major peak (peak IV) exhibited hemagglutinating activity. Data represent means $\pm \mathrm{SD}(n=6)$.

TABLE 2: Extraction of polysaccharides from four Chinese medicinal materials. Data represent means $\pm \operatorname{SD}(n=3)$.

\begin{tabular}{lcccc}
\hline & APS & PWP & IRP & ASP \\
\hline Medicinal materials (g) & 300.00 & 200.00 & 300.00 & 300.00 \\
Polysaccharide weight (g) & $3.653 \pm 0.42$ & $1.22 \pm 0.15$ & $3.21 \pm 0.34$ & $3.55 \pm 0.31$ \\
Carbohydrate concentration (\%) & $86.24 \pm 6.32$ & $79.35 \pm 6.45$ & $72.58 \pm 7.34$ & $83.87 \pm 4.23$ \\
\hline
\end{tabular}

APS: Astragalus mongholicus polysaccharide, PWP: Poria cocos polysaccharide, IRP: indigowood root polysaccharide, ASP: Angelica sinensis polysaccharide.

final concentration of $6.25-200 \mu \mathrm{g} / \mathrm{mL}$ (Figure 4 (a)). The four CHPs all showed mitogenic activity when applied alone, and their mitogenic activities were enhanced when applied concurrently with red kidney bean lectin, among which $50 \mu \mathrm{g} / \mathrm{mL}$ APS with $12.5 \mu \mathrm{g} / \mathrm{mL}$ red kidney bean lectin showed the highest mitogenic activity (Figure 4 (b)).

\subsection{Effects of Concurrent Application of APS and Red Kidney} Bean Lectin on Mouse Immune Function. Immune organ indices were calculated to evaluate the effects of APS and red kidney bean lectin on mouse immune functions. It was found that $100 \mathrm{mg} / \mathrm{kg} / \mathrm{bw}$ APS with $12.5 \mathrm{mg} / \mathrm{kg} / \mathrm{bw}$ red kidney bean lectin increased the mouse spleen index, but there were no significant differences in the thymus index between the treated groups and control groups (Table 3 ). The APS group and concurrent application of APS with moderate and high doses of red kidney bean lectin increased the phagocytosis activity of macrophages.

\section{Discussion}

4.1. Extraction of Red Kidney Bean Lectin. Lectins possess many bioactivities that may have important practical applications, but the high price resulting from the low extraction
TABLE 3: Effects of concurrent application of APS and red kidney bean lectin on the spleen and thymus indices and phagocytosis of $M_{\Phi}$ of mouse. Data represent means $\pm \mathrm{SD}(n=10)$.

\begin{tabular}{lccc}
\hline group & $\begin{array}{c}\text { Spleen index } \\
(\mathrm{mg} / \mathrm{g} / \mathrm{bw})\end{array}$ & $\begin{array}{c}\text { Thymus } \\
\text { index } \\
(\mathrm{mg} / \mathrm{g} / \mathrm{bw})\end{array}$ & $\begin{array}{c}\text { Phagocytic } \\
\text { index } \alpha \text { of } M_{\Phi}\end{array}$ \\
\hline Control & $4.71 \pm 0.65$ & $2.06 \pm 0.45$ & $4.06 \pm 0.82$ \\
Lectin control & $4.75 \pm 0.90$ & $2.06 \pm 0.53$ & $4.47 \pm 1.11$ \\
APS & $5.00 \pm 0.80$ & $2.15 \pm 0.61$ & $5.33 \pm 1.42^{*}$ \\
Low dose & $4.85 \pm 0.65$ & $2.19 \pm 0.81$ & $4.69 \pm 0.93$ \\
Middle dose & $5.46 \pm 0.85^{*}$ & $2.09 \pm 0.43$ & $5.42 \pm 0.90^{* *}$ \\
High dose & $6.50 \pm 1.04^{* *}$ & $2.28 \pm 0.65$ & $5.81 \pm 1.38^{* *}$ \\
\hline
\end{tabular}

APS: Astragalus Polysaccharides.

Control: normal saline; Lectin group: $12.5 \mathrm{mg} / \mathrm{kg} / \mathrm{bw}$ red kidney bean lectin; APS group: $100 \mathrm{mg} / \mathrm{kg} / \mathrm{bw}$ APS; Low dose group: $12.5 \mathrm{mg} / \mathrm{kg} / \mathrm{bw}$ lectin $+25 \mathrm{mg} / \mathrm{kg} / \mathrm{bw}$ APS; Moderate dose group: $12.5 \mathrm{mg} / \mathrm{kg} / \mathrm{bw}$ lectin + $50 \mathrm{mg} / \mathrm{kg} / \mathrm{bw}$ APS; High dose group: $12.5 \mathrm{mg} / \mathrm{kg} / \mathrm{bw}$ lectin $+100 \mathrm{mg} / \mathrm{kg} / \mathrm{bw}$ APS. Data were analyzed by one-way analysis of variance. ${ }^{*} P<.05$, ${ }^{*} P<$ .01 , compared with the control group.

rate restricts practical application of lectins. In this study a novel method, reversed micelles, was used to extract red kidney bean lectins. Reversed micelles represent water 
microdrops dispersed in an apolar aprotic solvent (oil). The interface between the water and apolar liquid is stabilized by a monolayer of surfactant molecules, the polar heads of which are in contact with the aqueous phase, whereas the hydrocarbon radicals are directed inside the oil phase. Reverse micellar systems have been utilized for extraction and purification of proteins since the 1990s [26, 27]. Nascimento et al. [20] used reverse micelles to extract affinitypurified lectin from Cratylia mollis seeds, of which the extraction and back extraction rate were both $100 \%$. In the present study, the utility of AOT/isooctane reversed micelles for lectin extraction was evaluated. The optimal conditions were found to be extraction at $\mathrm{pH} 4-6$ and back extraction at $\mathrm{pH} 9-11$, an aqueous phase ionic strength of $0.15 \mathrm{M} \mathrm{NaCl}$, extraction for 4-6 minutes and back extraction for 8 minutes. Extraction and back extraction of reversed micelles is very fast and both completed in a few minutes. Compared to the tedious operations of traditional extraction methods, reversed micelles were shown to have much greater efficiency. The efficacy of degreasing with both traditional methods and reversed micelles was investigated, and degreasing was demonstrated to be conducive to the separation of red kidney bean lectin. Reversed micelles resulted in a higher extraction rate and higher hemagglutinating activity than the three traditional methods, and the protein extraction rate from degreased bean powder with reversed micelles was $31.60 \%$ higher than that with the degreasing method (the best of the three traditional methods). The total hemagglutinating activity of reversed micelles was $99.80 \%$ higher than that of the degreasing method $\left(10.23 \times 10^{4}\right.$ and $5.12 \times 10^{4}$, resp. $)$. Therefore, reversed micelles were considered to be a superior method to extract lectins.

4.2. Purification of Red Kidney Bean Lectin by Column Chromatography. Methods for purifying lectins differ from one to another according to the source of the lectins, but classical protein purification methods, such as salting out and different chromatographic methods $[6,28,29]$, are still the basic methods used to purify lectins. In this study the purification procedure involved ion-exchange chromatography on DEAE Sephadex A-50 and sieve chromatography on Sephadex G150 columns. The purified lectin represented by fraction IV appeared as a single band with a molecular mass of $30 \mathrm{kDa}$ in SDS-PAGE, which demonstrated that the purification strategies were effective.

4.3. Mitogenic Activity of Red Kidney Bean Lectin and Four CHPs . Mitogenic activity has been identified in many leguminous species, such as knife beans [30] and anasazi beans [6]. Phytohemagglutinin (PHA; lectin extracted from Phaseolus vulgaris) and concanavalin A (ConA; lectin extracted from Canavalia gladiata) are the two main mitogens used in cell proliferation experiments in vitro. Concentrations of PHA used in cell proliferation assays in vitro differ according to the kidney bean cultivar and breeding location, the purpose and method of the assay, and source of PHA; the ultimate concentration of PHA obtained from Sigma has varied from $0.04 \mu \mathrm{g} / \mathrm{mL}$ [31] to $1 \mu \mathrm{g} / \mathrm{mL}$ [32], $5 \mu \mathrm{g} / \mathrm{mL}$ [33, 34], $10 \mu \mathrm{g} / \mathrm{mL}[35-38], 14 \mu \mathrm{g} / \mathrm{mL}$ [39], $20 \mu \mathrm{g} / \mathrm{mL}[40]$,

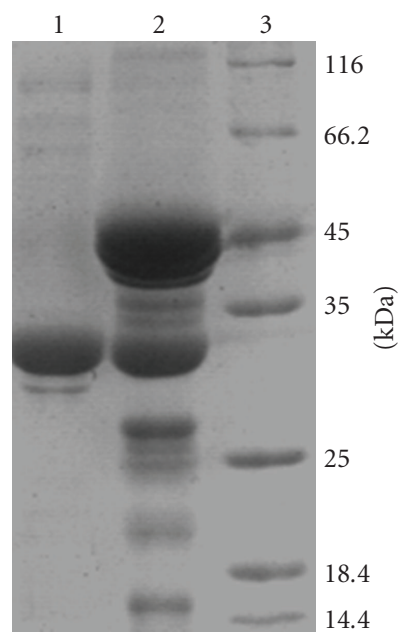

FIGURE 3: SDS-PAGE electrophoresis of red kidney bean lectin. Lane 1: purified red kidney bean lectin. Lane 2: crude red kidney bean lectin. Lane 3: molecular mass standards. From top downwards: $\beta$ galactosidase $(116.0 \mathrm{kDa})$, bovine serum albumin $(66.2 \mathrm{kDa})$, ovalbumin $(45.0 \mathrm{kDa})$, lactate dehydrogenase $(35.0 \mathrm{kDa})$, REase Bsp981 $(25.0 \mathrm{kDa}), \beta$-lactoglobulin $(18.4 \mathrm{kDa})$, and lysozyme $(14.4 \mathrm{kDa})$.

and $25 \mu \mathrm{g} / \mathrm{mL}$ [41], and that from Shanghai Yihua [42] and Tianjin Guangfu [43] is $10 \mu \mathrm{g} / \mathrm{mL}$. This article demonstrated that red kidney bean lectin can notably stimulate splenic lymphocyte proliferation at concentrations from 6.5 to $200 \mu \mathrm{g} / \mathrm{mL}$. Thus, compared with commercial PHA, this lectin has potential practical applications as a mitogen.

Astragalus mongholicus, Poria cocos, Poria cocos, indigowood root and Angelica sinensis are four well-known traditional East Asian medicinal plants, polysaccharides of which are important ingredients with many beneficial functions [44-46]. A lot of CHPs have mitogenic activity, such as Astragalus polysaccharide, IRP and Chinese yam polysaccharide $[45,47]$. Mitogenic activities of polysaccharides from these four plants were studied in the presence or absence of red kidney bean lectin. All four polysaccharides were shown to possess mitogenic activity, and the activity was enhanced when the CHPs were applied concurrently with red kidney bean lectin, among which joint application of APS with red kidney bean lectin exhibited the strongest mitogenic activity. Herbal polysaccharides exert immunoregulatory effects by different and complex mechanisms, including modulating the Th1/Th2 ratio, phagocytosis activity of macrophages, of NK cell activity and secretion of cytokines. Mitogenic activities of polysaccharides have been studied for decades, but the mechanisms are still unclear. In this study the mitogenic activities of APS, IRP, and PWP were suppressed at a high concentration, which has been reported in previous studies $[48,49]$. Reasons for this phenomenon might be the proliferation of Ts cells or presence of cytotoxic contaminants in the polysaccharides.

4.4. Influence of Red Kidney Bean Lectin and APS on Mouse Immune Function. Macrophages are an important component of host defenses against viral infection by inhibiting 


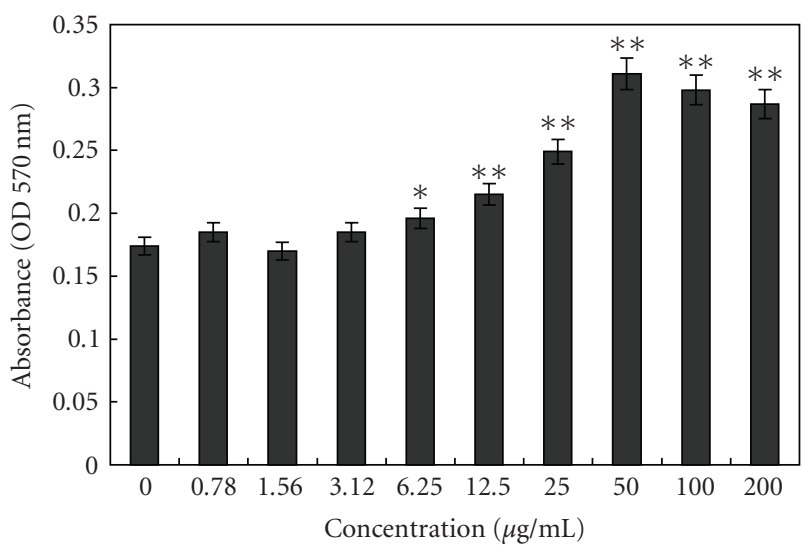

(a)

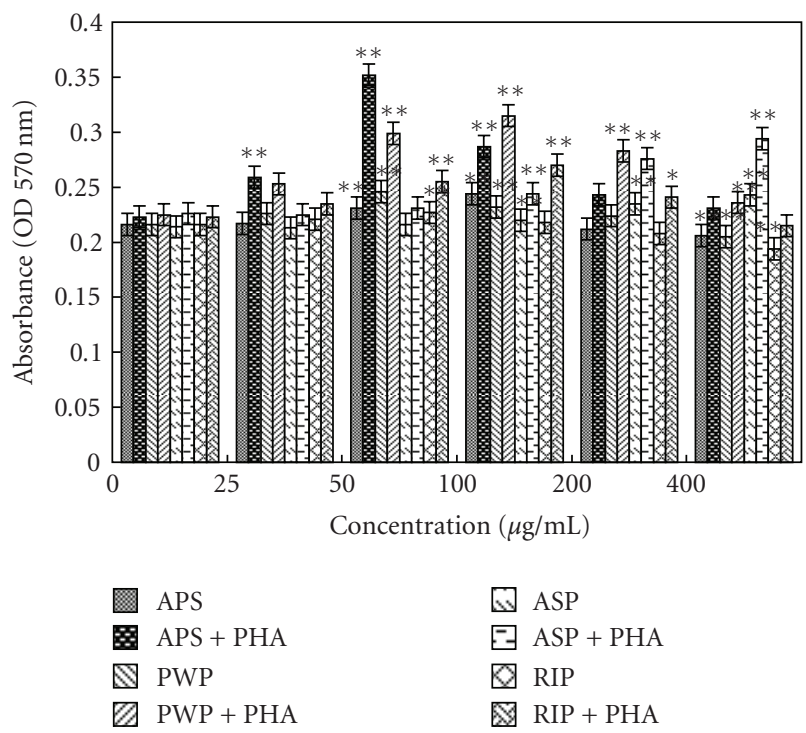

(b)

Figure 4: (a) Effect of red kidney bean lectin on multiplication of mouse splenic lymphocytes $\left(\mathrm{OD}_{570}\right.$ value). (b) Influence of CHPs applied separately, and concurrent application of CHPs with $12.5 \mu \mathrm{g} / \mathrm{mL}$ red kidney bean lectin, on multiplication of mouse splenic lymphocytes ( $\mathrm{OD}_{570}$ value). CHP: Chinese herbal polysaccharide; APS: Astragalus mongholicus polysaccharide; PWP: Poria cocos polysaccharide; ASP: Angelica sinensis polysaccharide; IRP: indigowoad root polysaccharide. Data represent means \pm SD $(n$ $=3$ ). Data were analyzed by one-way analysis of variance. ${ }^{*} P<.05$, ${ }^{* *} P<.01$, compared with CHP applied alone.

intracellular replication of viruses and by killing virusinfected cells [50]. When activated, a variety of oxygen or nitrogen intermediates and cytokines are released from macrophages and participate in various important biological functions, such as anti-inflammatory and anti-tumor activities $[44,51,52]$. Therefore, phagocytic activity of macrophages is an important indicator of organism immune functions. Many herbal polysaccharides can enhance phagocytic activity of macrophages [44, 53, 54]. In this study APS augmented the phagocytic activity of macrophages, which increased 9.07\% when APS and red kidney bean lectin were applied concurrently. Joint application of APS and red kidney bean lectin also increased the spleen index, whereas application of APS and red kidney bean lectin alone did not. Thus, enhancements in effects were apparent when herbal polysaccharides were applied concurrently with red kidney bean lectin, which is a very important finding considering the high cost and time-consuming nature of the extraction procedures.

\section{References}

[1] E. M. Etzler, "Distribution and function of plant lectins," in The Lectins, I. E. Liener, N. Sharon, and L. J. Goldstein, Eds., pp. 371-435, Academic Press, San Diego, Calif, USA, 1986.

[2] E. J. M. Van Damme, W. J. Peumans, A. Barre, and P. Rougé, "Plant lectins: a composite of several distinct families of structurally and evolutionary related proteins with diverse biological roles," Critical Reviews in Plant Sciences, vol. 17, no. 6, pp. 575-692, 1998.

[3] N. Sharon and H. Lis, Lectins, Kluwer Academic Publishers, Dordrecht, The Netherlands, 2nd edition, 2003.

[4] K. V. Brinda, A. Surolia, and S. Vishveshwara, "Insights into the quaternary association of proteins through structure graphs: a case study of lectins," Biochemical Journal, vol. 391, no. 1, pp. 1-15, 2005.

[5] N. N. Nagre, V. B. Chachadi, P. B. Sundaram, et al., "A potent mitogenic lectin from the mycelia of a phytopathogenic fungus, Rhizoctonia bataticola, with complex sugar specificity and cytotoxic effect on human ovarian cancer cells," Glycoconjugates Journal, vol. 27, pp. 375-386, 2010.

[6] A. Sharma, T. B. Ng, J. H. Wong, and P. Lin, "Purification and characterization of a lectin from Phaseolus vulgaris $c v$. (Anasazi Beans)," Journal of Biomedicine and Biotechnology, vol. 2009, Article ID 929568, 9 pages, 2009.

[7] L. G. Barrientos and A. M. Gronenborn, "The highly specific carbohydrate-binding protein cyanovirin-N: structure, anti-HIV/Ebola activity and possibilities for therapy," MiniReviews in Medicinal Chemistry, vol. 5, no. 1, pp. 21-31, 2005.

[8] E. C. van Asbeck, A. I. M. Hoepelman, J. Scharringa, B. L. Herpers, and J. Verhoef, "Mannose binding lectin plays a crucial role in innate immunity against yeast by enhanced complement activation and enhanced uptake of polymorphonuclear cells," BMC Microbiology, vol. 8, pp. 229-238, 2008.

[9] Y. Luo, X. Xu, J. Liu et al., "A novel mannose-binding tuber lectin from Typhonium divaricatum (L.) Decne (family Araceae) with antiviral activity against HSV-II and antiproliferative effect on human cancer cell lines," Journal of Biochemistry and Molecular Biology, vol. 40, no. 3, pp. 358367, 2007.

[10] N. Rubinstein, J. M. Ilarregui, M. A. Toscano, and G. A. Rabinovich, "The role of galectins in the initiation, amplification and resolution of the inflammatory response," Tissue Antigens, vol. 64, no. 1, pp. 1-12, 2004.

[11] T. Singh, J. H. Wu, W. J. Peumans et al., "Carbohydrate specificity of an insecticidal lectin isolated from the leaves of Glechoma hederacea (ground ivy) towards mammalian glycoconjugates," Biochemical Journal, vol. 393, no. 1, pp. 331341, 2006.

[12] K. Feng, Q. H. Liu, T. B. Ng et al., "Isolation and characterization of a novel lectin from the mushroom Armillaria luteo-virens," Biochemical and Biophysical Research Communications, vol. 345, no. 4, pp. 1573-1578, 2006. 
[13] C. Bies, C.-M. Lehr, and J. F. Woodley, "Lectin-mediated drug targeting: history and applications," Advanced Drug Delivery Reviews, vol. 56, no. 4, pp. 425-435, 2004.

[14] J. Li, H. Wu, J. Hong et al., "Odorranalectin is a small peptide lectin with potential for drug delivery and targeting," PLOS ONE, vol. 3, no. 6, article e2381, 2008.

[15] E. G. de Mejía and V. I. Prisecaru, "Lectins as bioactive plant proteins: a potential in cancer treatment," Critical Reviews in Food Science and Nutrition, vol. 45, no. 6, pp. 425-445, 2005.

[16] X. Y. Ye, T. B. Ng, P. W. K. Tsang, and J. Wang, "Isolation of a homodimeric lectin with antifungal and antiviral activities from red kidney bean (Phaseolus vulgaris) seeds," Journal of Protein Chemistry, vol. 20, no. 5, pp. 367-375, 2001.

[17] E. L. Heinrich, L. A. Y. Welty, L. R. Banner, and S. B. Oppenheimer, "Direct targeting of cancer cells: a multiparameter approach," Acta Histochemica, vol. 107, no. 5, pp. 335-344, 2005.

[18] I. A. Schepetkin and M. T. Quinn, "Botanical polysaccharides: macrophage immunomodulation and therapeutic potential," International Immunopharmacology, vol. 6, no. 3, pp. 317-333, 2006.

[19] S. Wasser, "Medicinal mushrooms as a source of antitumor and immunomodulating polysaccharides," Applied Microbiology and Biotechnology, vol. 60, no. 3, pp. 258-274, 2002.

[20] C. O. Nascimento, L. C. B. B. Coelho, M. T. S. Correia, and M. G. Carneiro-Da-Cunha, "Liquid-liquid extraction of lectin from Cratylia mollis seeds using reversed micelles," Biotechnology Letters, vol. 24, no. 11, pp. 905-907, 2002.

[21] M. M. Bradford, "A rapid and sensitive method for the quantitation of microgram quantities of protein utilizing the principle of protein dye binding," Analytical Biochemistry, vol. 72, no. 1-2, pp. 248-254, 1976.

[22] U. K. Laemmli and M. Favre, "Gel electrophoresis of proteins," Journal of Molecular Biology, vol. 80, no. 4, pp. 575-599, 1973.

[23] N. Alam and P. C. Gupta, "Structure of a water-soluble polysaccharide from the seeds of Cassia angustifolia," Planta Medica, vol. 4, pp. 308-310, 1986.

[24] M. Dubois, K. Gilles, J. K. Hamilton, P. A. Rebers, and F. Smith, "A colorimetric method for the determination of sugars," Nature, vol. 168, no. 4265, p. 167, 1951.

[25] W.-X. Zhang, Immunology Techniques, Science, Beijing, China, 2007.

[26] A. Pessoa Jr. and M. Vitolo, "Separation of inulinase from Kluyveromyces marxianus using reversed micellar extraction," Biotechnology Techniques, vol. 11, no. 6, pp. 421-422, 1997.

[27] E. M. G. Rodrigues, A. M. F. Milagres, and A. Pessoa Jr., "Xylanase recovery: effect of extraction conditions on the AOT-reversed micellar systems using experimental design," Process Biochemistry, vol. 34, no. 2, pp. 121-125, 1999.

[28] J. Shi, S. J. Xue, Y. Kakuda, S. Ilic, and D. Kim, "Isolation and characterization of lectins from kidney beans (Phaseolus vulgaris)," Process Biochemistry, vol. 42, no. 10, pp. 1436-1442, 2007.

[29] J. A. Silva, D. C. S. Damico, P. A. Baldasso et al., "Isolation and biochemical characterization of a galactoside binding lectin from Bauhinia variegata candida (BvcL) seeds," Protein Journal, vol. 26, no. 3, pp. 193-201, 2007.

[30] J. H. Wong and T. B. Ng, "Isolation and characterization of a glucose/mannose/rhamnose-specific lectin from the knife bean Canavalia gladiata," Archives of Biochemistry and Biophysics, vol. 439, no. 1, pp. 91-98, 2005.

[31] A. Anteunis, "Origin and fate of the multivesicular bodies in PHA stimulated lymphocytes," Cell and Tissue Research, vol. 149, no. 4, pp. 497-511, 1974.
[32] J.-J. Shan, Y. Wang, S.-C. Wang, D. Liu, and Z.-B. Hu, "Effect of Angelica sinensis polysaccharides on lymphocyte proliferation and induction of IFN- $\gamma$," Acta Pharmaceutica Sinica, vol. 37, no. 7, pp. 497-500, 2002.

[33] A. Pawlik, M. Baskiewicz-Masiuk, B. Machalinski, and B. Gawronska-Szklarz, "Involvement of P-gp in the process of apoptosis in peripheral blood mononuclear cells," International Immunopharmacology, vol. 5, no. 5, pp. 821-828, 2005.

[34] M. Saito, T. Yamaguchi, T. Kawata et al., "Effect of methamphetamine on cortisone concentration, NK cell activity and mitogen response of T-lymphocytes in female cynomolgus monkeys," Experimental Animals, vol. 55, no. 5, pp. 477-481, 2006.

[35] B. Wirleitner, K. Schroecksnadel, C. Winkler, H. Schennach, and D. Fuchs, "Resveratrol suppresses interferon- $\gamma$-induced biochemical pathways in human peripheral blood mononuclear cells in vitro," Immunology Letters, vol. 100, no. 2, pp. 159-163, 2005.

[36] M. Jenny, C. Winkler, M. Spetea, H. Schennach, H. Schmidhammer, and D. Fuchs, "Non-peptidic $\delta$-opioid receptor antagonists suppress mitogen-induced tryptophan degradation in peripheral blood mononuclear cells in vitro," Immunology Letters, vol. 118, no. 1, pp. 82-87, 2008.

[37] G. Girgin, T. Baydar, M. Ledochowski et al., "Immunomodulatory effects of Turkish propolis: changes in neopterin release and tryptophan degradation," Immunobiology, vol. 214, no. 2, pp. 129-134, 2009.

[38] C. Winkler, B. Frick, K. Schroecksnadel, H. Schennach, and D. Fuchs, "Food preservatives sodium sulfite and sorbic acid suppress mitogen-stimulated peripheral blood mononuclear cells," Food and Chemical Toxicology, vol. 44, no. 12, pp. 20032007, 2006.

[39] F. Yan, Preparation of Pilose Antler Oral Liquid and Effect on Immunological Function in Mice, Northwest Agriculture and Forest University, Yangling, China, 2008.

[40] P. Conti, M. G. Cifone, E. Alesse, M. Reale, E. Boidi, and T. Williams, "Effect of supernatants from PHA-stimulated and non-stimulated lymphocyte cultures on thromboxane B2 release by polymorphonuclear leukocytes in vitro," Agents and Actions, vol. 16, no. 1-2, pp. 52-54, 1985.

[41] N.-Q. Yao, Detection of Cell-Mediated Immunity of CSF Ultra Pre-Immunity, Jilin Agriculture University, Jilin, China, 2007.

[42] W.-F. He, Effects of Umbilical Cord Blood Mesenchymal Stem Cell on PHA Induced Lymphocytes Proliferation, NanChang University Medical School, NanChang, China, 2006.

[43] Y.-P. Wang, Study on Chinese Herbs Property about Sweet, Cold and Channel Tropism of the Gan and Shen: Immune Function Effect on Immunosuppressive Mice, HeFei University of Technology, HeFei, China, 2007.

[44] Y. Chen, J.-A. Duan, D. Qian, et al., "Assessment and comparison of immunoregulatory activity of four hydrosoluble fractions of Angelica sinensis in vitro on the peritoneal macrophages in ICR mice," International Immunopharmacology, vol. 10, pp. 422-430, 2010.

[45] Y. Qiu, Y. L. Hu, B. A. Cui et al., "Immunopotentiating effects of four Chinese herbal polysaccharides administered at vaccination in chickens," Poultry Science, vol. 86, no. 12, pp. 2530-2535, 2007.

[46] X.-F. Kong, Y.-L. Hu, Y.-L. Yin et al., "Chinese herbal ingredients are effective immune stimulators for chickens infected with the newcastle disease virus," Poultry Science, vol. 85, no. 12, pp. 2169-2175, 2006. 
[47] X. Kong, Y. Hu, R. Rui, D. Wang, and X. Li, "Effects of Chinese herbal medicinal ingredients on peripheral lymphocyte proliferation and serum antibody titer after vaccination in chicken," International Immunopharmacology, vol. 4, no. 7, pp. 975-982, 2004.

[48] J. L. Ríos and P. G. Waterman, "A review of the pharmacology and toxicology of Astragalus," Phytotherapy Research, vol. 11, no. 6, pp. 411-418, 1997.

[49] H. Iwama, S. Amagaya, and Y. Ogihara, "Effects of five kampohozais on the mitogenic activity of lipopolysaccharide, concanavalin A, phorbol myristate acetate and phytohemagglutinin in vivo," Journal of Ethnopharmacology, vol. 18, no. 2, pp. 193-204, 1986.

[50] E.-M. Choi, A.-J. Kim, Y.-O. Kim, and J.-K. Hwang, "Immunomodulating activity of Arabinogalactan and Focoidan in vitro," Journal of Medicinal Food, vol. 8, no. 4, pp. 446-453, 2005.

[51] Y. S. Lee, O. K. Han, C. W. Park, et al., "Pro-inflammatory cytokine gene expression and nitric oxide regulation of aqueous extracted Astragali radix in RAW 264.7 macrophage cells," Journal of Ethnopharmacology, vol. 100, no. 3, pp. 289294, 2005.

[52] K. Y. Lee and Y. J. Jeon, "Polysaccharide isolated from Poria cocos sclerotium induces NF- $\kappa \mathrm{B} /$ Rel activation and iNOS expression in murine macrophages," International Immunopharmacology, vol. 3, no. 10-11, pp. 1353-1362, 2003.

[53] M. P. Moretão, D. F. Buchi, P. A. J. Gorin, M. Iacomini, and M. B. M. Oliveira, "Effect of an acidic heteropolysaccharide (ARAGAL) from the gum of Anadenanthera colubrina (Angico branco) on peritoneal macrophage functions," Immunology Letters, vol. 89, no. 2-3, pp. 175-185, 2003.

[54] J.-Y. Shin, J.-Y. Song, Y.-S. Yun, H.-O. Yang, D.-K. Rhee, and S. Pyo, "Immunostimulating effects of acidic polysaccharides extract of Panax ginseng on macrophage function," Immunopharmacology and Immunotoxicology, vol. 24, no. 3, pp. 469-482, 2002. 

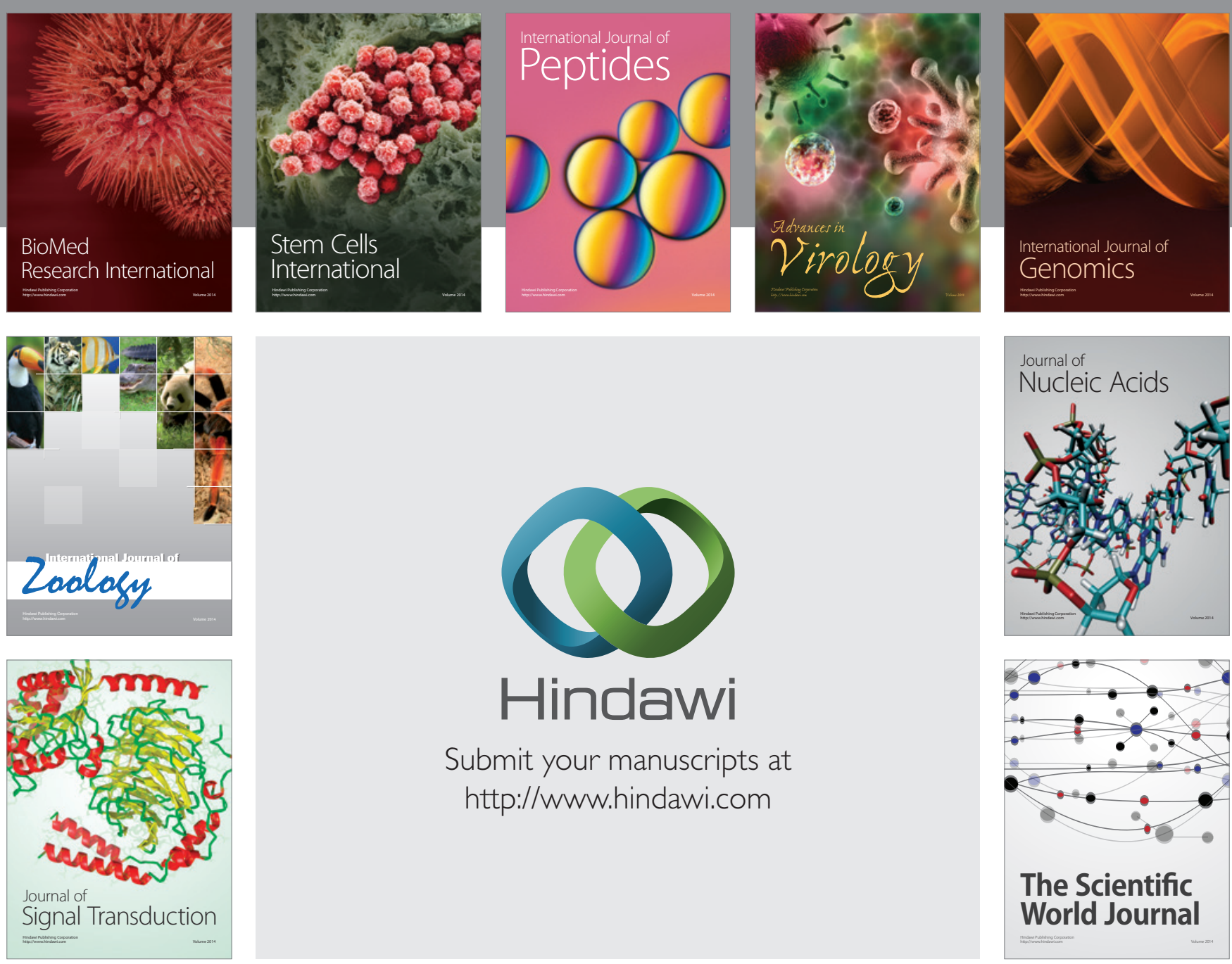

Submit your manuscripts at

http://www.hindawi.com
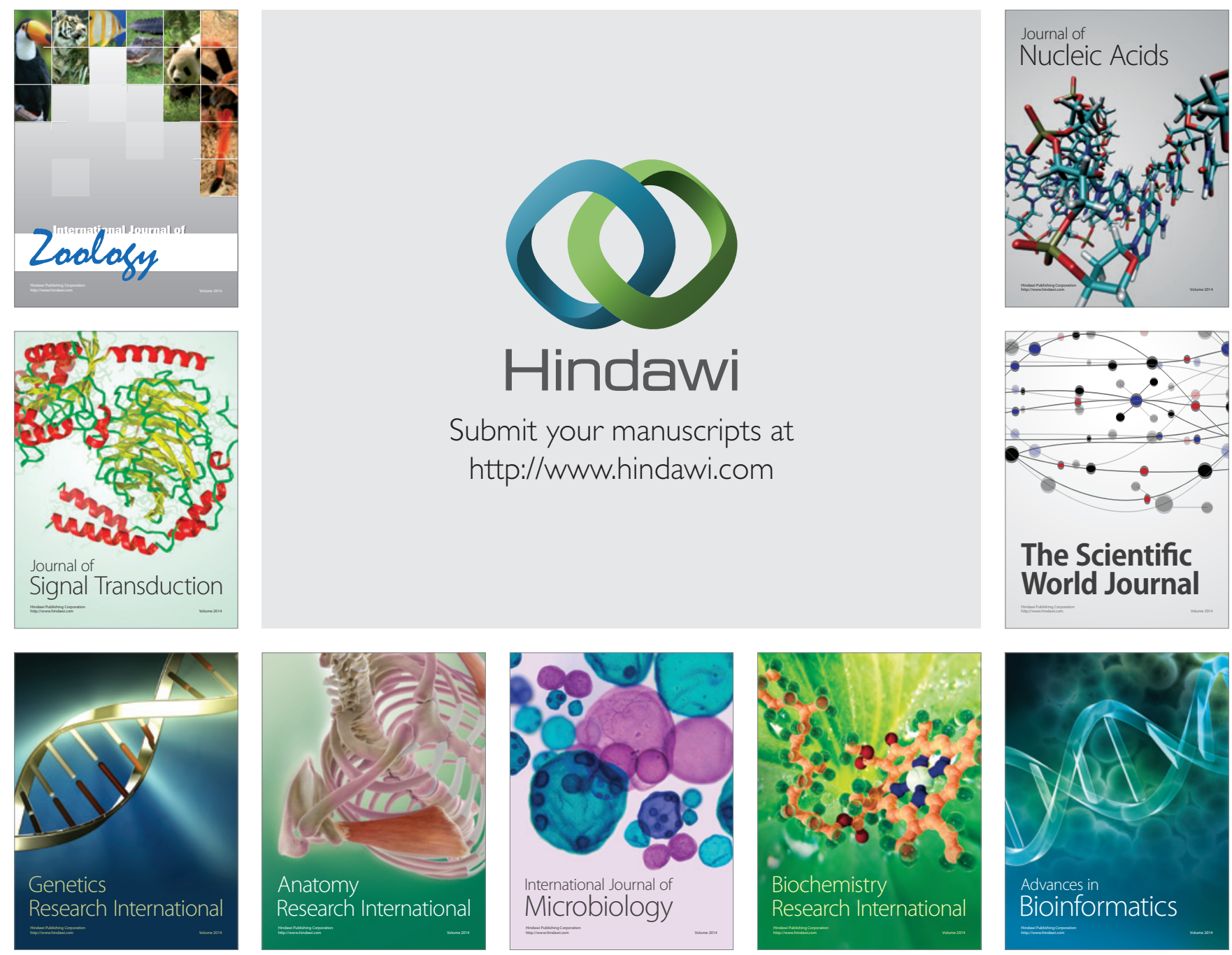

The Scientific World Journal
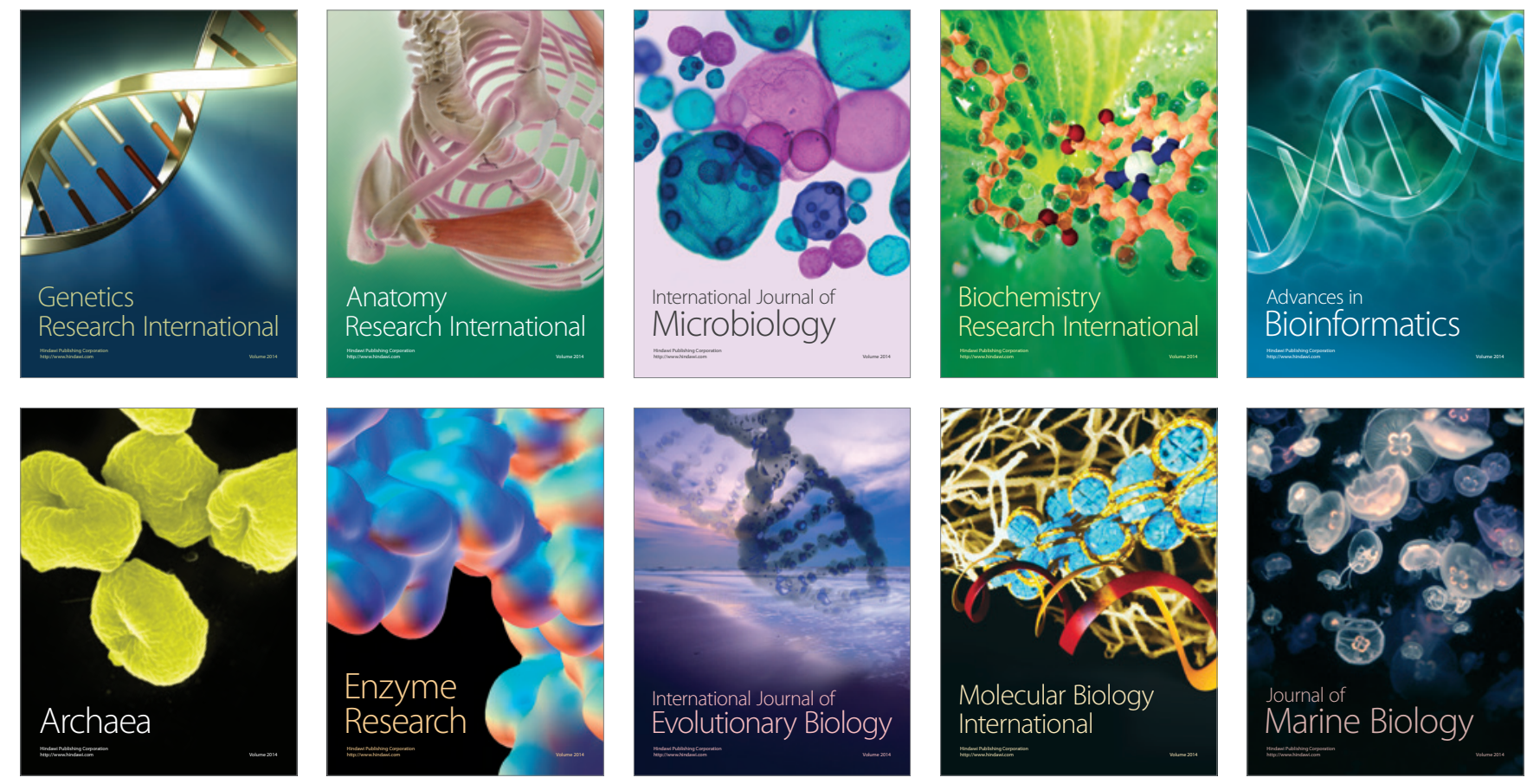